\title{
Predictor of Diabetes: Correlation between Leucine Concentration and Insulin Resistance
}

\author{
Chyntia R. Wijaya ${ }^{1,3}$, Indriyanti R. Sukmana ${ }^{2}$, Jutti Levita ${ }^{3}$ \\ ${ }^{1}$ Prodia Clinical Laboratory, Semarang, Central Java, Indonesia \\ ${ }^{2}$ Prodia Clinical Laboratory, Central Jakarta, Special Capital Distric of Jakarta, Indonesia \\ ${ }^{3}$ Department of Pharmacology and Clinical Pharmacy, Universitas Padjadjaran, Jatinangor, \\ West Java, indonesia
}

\begin{abstract}
Leucine catabolism changes among people with central obesity. This condition can lead to metabolic pathway disorder and increased mTORC-1 activation. Downstream signal of mTORC-1 is p70S6K1, which causes phosphorylation of insulin-1 receptor substrate (IRC1). This study was performed to evaluate correlation between leucine concentration and insulin resistance (IR). This study was a prospective cross-sectional study, involving two groups; control and obese group. General characteristics and blood sample were taken from each subject. Leucin and Homeostasis Model Assesment (HOMA)-IR, as the marker of insulin resistance, were evaluated. Leucin concentration was measured using previously validated Liquid Chromatography Mass Spectrometry (LC-MS) system. The result indicated a significant positive correlation between leucine concentration and insulin resistance value $(\mathrm{R}=0.351 ; \mathrm{P}=0.006)$ in central obese men. The higher leucine concentration, the higher the risk of insulin resistance occurrance. Therefore, leucine can be used as a biomarker for early detection of insulin resistance.
\end{abstract}

Keywords: amino acids, mTORC-1, insulin-1 receptor substrate

\section{Introduction}

Obesity is one of the global health issues. Imbalance between lack of physical activities and excessive nutrition intake cause metabolism disorder and visceral fat accumulation which lead to adipose hypertrophy, particularly in abdomen. ${ }^{1}$ Adipose hypertrophy could stimulate the production of various proinflammatory cytokines, which spread into other tissues, such as liver and muscles that trigger the insulin resistance. ${ }^{2}$ Insulin resistance is a physiological condition where target organs, including skeletal muscle, adipose tissue, and liver cell fail to respond insulin action effectively. Sistemic insulin resistance in obesity begins mostly in adipose tissue disfunction through macrofagmediated inflammation. Adipose tissue can

Corresponding author: Chyntia R. Wijaya. Prodia Clinical Laboratory, Semarang, Central Java, Indonesia. Email: chyntia. resti@prodia.co.id

Received: 3 September 2017. Revised: 7 November 2017. Published: 1 December 2017 
communicate with liver and other organs such as liver muscle and pancreas, and releases proinflammatory cytokines which cause decreased insulin sensitivity. ${ }^{3}$

Progress of type 2 diabetes mellitus (T2DM) in obese individual begins with beta cell disfunction induced by insulin resistance and lipotoxicity so that it decreases insulintropic GLP-1 action. ${ }^{4,5}$ Measurement of insulin resistance using Homeostasis Model Assesment (HOMA) approach has been developed to show the balance between hepatic glucose production and beta cell insulin secretion under basal homeostasis. HOMA insulin resistance is used to measure insulin resistance index that is obtained from calculation of fasting insulin concentration $x$ fasting glucose/22.5. Leucin is one of the amino acids that contributes in the progression of insulin resistance. ${ }^{6,7}$

Nevertheless, there is limited studies investigating predictive value of leucine as biomarker for type 2 diabetes. Previous studies were conducted in Western countries, while the evidence from Asian population are sparse. ${ }^{8}$ Therefore, this study was conducted to see the correlation between leucine concentration for diabetes risk early detection and insulin resistance in central obese men in Indonesia.

\section{Methods}

This experiment was a cross sectional study conducted at Prodia Clinic Laboratory Semarang, Bandung, Bogor, and Jakarta. This experiment was approved by Health Research Ethics Committe, Faculty of Medicine, Padjajaran University, with No. 3577/UN6.O.1/LT/2017. Informed consent was obtained from each subject. Included subjects were 60 male adults aged 30-50 years old, with abdominal circumference $>90 \mathrm{~cm}$ for central obesity group according to WHO criteria for regional Asia Pasific and 20 subjects with abdominal circumference $<90 \mathrm{~cm}$ as control group.

\section{Sample preparation}

One tube $(9 \mathrm{ml})$ of subjects' blood was taken from blood vessel in the elbow crease. SGOT, SGPT, creatinine, hsCRP, HbAlc, fasting blood glucose, insulin and leucine were measured. Subjects' blood was taken by using venipuncture technic by professionals. The blood in the SST tube then were kept for 30 minutes until cloted then were centrifuged (3000 RPM) for 15 minutes. The serum was aliquoted according to the examination type and was kept on temperature $-70^{\circ} \mathrm{C}$ for analysis. Blood sample taken using tube with anticoagulant EDTA then were inverted (approximately 10 times) to ensure anticoagulant and the blood were perfectly mixed.

\section{Measurement of leucine concentration}

$10 \mathrm{uL}$ leucin $(100 \mathrm{umol} / \mathrm{L})$ as the internal standard was mixed with $100 \mathrm{ml}$ serum. It was then homogenized using vortex for 30 seconds. $900 \mathrm{uL}$ methanol LC-MS grade were added until protein sediment was formed. The mixture then was homogenized for 2 minutes then was centrifuged (14000 rpm) for 10 minutes. $100 \mathrm{uL}$ supernatant was added with $500 \mathrm{uL}$ methanol $(50 \%)$ and were homogenized for 1 minute. The sample was then examined using LC-MS system. The examination has been developed and validated by Laboratory Mass Spectrometry PT. Prodia Widyahusada, Tbk.

\section{Data analysis}

T-test and correlation Pearson test was used to evaluate the correlation between leucine concentration and insulin resistance (HOMAIR). Analysis was calculates using SPSS 24. Significance level was set at 5\%. 


\section{Results and Discussion}

In this preliminary research, 80 subjects consisting of 20 non-central obese men as control and 60 central obese men were included (Table 1). There was significant difference on leucine concentration between central obesity and control, with higher concentration in central obese subjects. After further analysis by categorizing into obesity non-DM group $(\mathrm{HbA} 1 \mathrm{c}<6.4 \%)$, preDM (HbAlc 5.7-6.4\%) and DM (HbAlc $>6.5 \%$ ), the highest HOMA-IR value was found in DM patients. $(\mathrm{P}<0.001)$. This result showed that insulin resistance occurred in central obese subjects with increased $\mathrm{HbAlc}$ value.

Insulin resistance is not only caused by carbohydrate and fat metabolism disorders, but also protein. Some metabolomic studies have been done to identify new biomarker associated with insulin resistance that has prediabetes prediction value and T2DM, such as branched chain amino acids including leucine. Compared with the other amino acids, leucine indicates the highest insulinogenic index so that it plays important role in mTORC-1 regulation, beta cell growth, beta cell proliferation and insulin secretion. Activation of mTORC-1 depends on adequate supply of branched chain amino acids especially leucine. ${ }^{8}$ Leucine acts as nutrient signal, managing protein synthesis, and degradation and secretion of insulin as potential Mammalian Target of Rapamycin Complex-1 (mTORC-1) activator and increased glucose uptake through phosphorylation Akt in adipose tissue. ${ }^{9-10}$

Leucine is one of the amino acids containing more than $20 \%$ of total protein food. At physiological concentration, leucine regulates gen transcription and protein synthesis in pancreatic beta cell through either dependent pathway or independent pathway in mTORC-1. ${ }^{9}$ Leucine's role in insulin resistance pathogenesis as marker that energy metabolic pathways disorder has occured. There is an excessive energy

Table 1. General Characteristics of Subjects

\begin{tabular}{|c|c|c|c|c|c|c|c|}
\hline \multirow{3}{*}{ Variable } & \multicolumn{6}{|c|}{ Subject Group } & \multirow{3}{*}{$\mathbf{p}$} \\
\hline & \multicolumn{3}{|c|}{ Control $(n=20)$} & \multicolumn{3}{|c|}{ Central Obesity $(n=60)$} & \\
\hline & Mean & (SD) & Median & Mean & SD & Median & \\
\hline Age (year) & 39.0 & $(7.0)$ & 36.5 & 40.0 & $(6.0)$ & 40.5 & 0.459 \\
\hline Waist (cm) & 81.4 & (7.4) & 85.0 & 106.1 & $(8.2)$ & 103.5 & $0.000 *$ \\
\hline BMI (kg/m2) & 23.2 & $(2.6)$ & 24.0 & 32.0 & $(4.3)$ & 31.0 & $0.000 *$ \\
\hline SGOT (U/l) & 20.4 & $(4.7)$ & 19.0 & 26.1 & (8.4) & 25.5 & $0.000 *$ \\
\hline SGPT (U/l) & 20.1 & (9.6) & 18.5 & 38.1 & $(18.7)$ & 34.5 & $0.000 *$ \\
\hline Fasting glucose (mg/dl) & 87.2 & $(9.4)$ & 89.0 & 101.7 & $(41.3)$ & 88.5 & 0.672 \\
\hline Insulin (uIU/ml) & 4.4 & $(2.7)$ & 3.5 & 13.7 & $(9.2)$ & 11.3 & $0.000 *$ \\
\hline HOMA-IR & 1.0 & $(0.7)$ & 0.8 & 3.8 & (3.9) & 2.7 & $0.000 *$ \\
\hline HOMA-B & 68.4 & $(33.2)$ & 72.5 & 171.2 & (101.4) & 173.5 & $0.000 *$ \\
\hline HbA1c (\%) & 5.2 & $(0.2)$ & 5.3 & 6.2 & (1.7) & 5.7 & $0.000 *$ \\
\hline $\begin{array}{l}\text { eGFR (ml/minute } / 1.73 \\
\mathrm{~m} 2)\end{array}$ & 98.2 & $(11.2)$ & 102.0 & 102.7 & $(12.8)$ & 104.0 & 0.123 \\
\hline
\end{tabular}


in obesity that will cause expression change and decreased activity of leucine metabolic enzyme that is BCATm in adipose tissue so that decreased leucine catabolism occurs and leucine increases in circulation. ${ }^{10,11}$

Increased leucine concentration in central obesity is in line with the mechanism in the progress into insulin resistance and DM. In obesity, there is expression change and decreased activity of enzyme transaminase in adipose tissue so that decreased leucine catabolism causes increased leucine in circulation. ${ }^{7}$ This condition causes change of metabolism pathway that is increased gluconeogenesis which is the signal for pancrease to increase insulin secretion and to activate mTORC-1. Hyperactivity of mTORC-1 activates p70S6K which cause serine phosphorylation and retardation of insulin-1 receptor substrate (IRS). This condition will disrupt insulin signal and IRS-1 degradation so that insulin resistance occurs. ${ }^{9-12}$

Change in metabolism pathway occured by increased leucine concentration causes gluconeogenesis, that is glucose production of amino acids in liver. High concentration of glucose from gluconeogenesis will increase signal so that pancreas secretes insulin continously and causes IGF-1 activates mTORC-1. Hyperactivity of mTORC-1 will activate p70 ribosomal S6 kinase (p70S6K) then serine phosphorylation takes place and resists insulin-1 receptor substrate (IRS). This condition will disrupt insulin signal and causes IRS-1 degradation so that insulin resistance occurs.

Our study highlight that this amino acid can be used as novel novel biomarker for predicting type 2 diabetes. Further research should be conducted to determine cut-off value of leucine concentration with positive predictive value of diabetes condition.

\section{Conclusion}

Leucine concentration in central obese men group significantly correlates with insulin resistance (HOMA-IR). The higher leucine concentration, the higher the risk of insulin resistance occurrance. Leucine can be used for early detection of insulin resistance.

\section{Acknowledgement}

Authors thank to Prodia Widyahusada Tbk PT for facilitating this work.

\section{Funding}

This work was funded by Prodia Widyahusada Tbk PT, Jakarta.

\section{Conflict of Interest}

None declared

\section{References}

1. Chang J, Chen H, Su H, dan Lee C. Abdominal obesity and insulin resistance in people exposed to moderate-tohigh levels of dioxin. PLOS ONE. 2016; $01: 45818$.

2. Esteghamati A, Ashraf H, Khalilzadeh O. Optimal cut-off of homeostasis model assessment of insulin resistance (HOMAIR) for the diagnosis of metabolic syndrome. Nutrition and Metabolism. 2007;1:26-35.

3. Hellmuth C, Kirchberg F, Lass N, Harder U, Peissner W, Koletzko B. Tyrosine is associated with insulin resistance in longitudinal metabolomic profiling of obese children,. Journal of Diabetes Research. 2016;10(11)1-10.

4. Lu J, Xie G, Jia W. Insulin resistance and the metabolism of branched-chain amino acid. Frontiers of Medicine. 2013;1:5359.

5. Destiani DP, Ghazali A. Drug related problems in patients with diabetic 
nephropathy at a tertiary hospital in Malaysia. Pharmacology and Clinical Pharmacy Research. 2016;1(2):42-47.

6. Madsbad. S. The role of glucagonlike peptide-1 impairment in obesity. Diabetes, Obesity and Metabolism. 2013;1:9-21.

7. Melnik A, Bodo C. Leucine signaling in the pathogenesis of type 2 diabetes and obesity. World Journal of Diabetes. 2012;3:38-42.

8. Tillin T. Diabetes risk and amino acid profiles: cross-sectional and prospective analyses of ethnicity, amino acids and diabetes in a South Asian and European cohort. Diabetologia. 2015;58:968-979.

9. Yang J, Chi Y, Burkhardt B. Leucine metabolism in regulation of insulin secretion from pancreatic beta cells, Nutrition Reviews. 2012;5:270-279.

10. Zhao X, Han Q, Liu Y, Sun C, Gang X. The relationship between branched-chain amino acid related metabolomic signature and insulin resistance: a systematic review. Journal of Diabetes Research. 2016;1:1-12.

11. Blicharski T, Tomaszewska E, Dobrowolski P, Hułas-Stasiak M. A metabolite of leucine ( $\beta$-hydroxy- $\beta$ methylbutyrate) given to sows during pregnancy alters bone development of their newborn offspring by hormonal modulation. PLoS One. 2017;12(6):e0179693.

12. Duan Y, Li F, Li Y, Tang Y, Kong X, Feng $Z$, et al. The role of leucine and its metabolites in protein and energy metabolism. Amino Acids. 2016;48: 4151. 